Article

\title{
Berberine Enhances the Antibacterial Activity of Selected Antibiotics against Coagulase-Negative Staphylococcus Strains in Vitro
}

\author{
Robert D. Wojtyczka ${ }^{1}{ }^{*}$, Arkadiusz Dziedzic ${ }^{2}$, Malgorzata Kępa ${ }^{1}$, Robert Kubina ${ }^{3}$, \\ Agata Kabała-Dzik $^{3}$, Tomasz Mularz ${ }^{1}$ and Danuta Idzik ${ }^{1}$
}

1 Department and Institute of Microbiology and Virology, School of Pharmacy and Division of Laboratory Medicine in Sosnowiec, Medical University of Silesia, Katowice, ul. Jagiellońska 4, 41-200 Sosnowiec, Poland; E-Mails: mkepa@sum.edu.pl (M.K.); tomekmularz@aol.com (T.M.); didzik@sum.edu.pl (D.I.)

2 Department of Conservative Dentistry with Endodontics, Medical University of Silesia, Katowice, Pl. Akademicki 17, 41-902 Bytom, Poland; E-Mail: adziedzic@sum.edu.pl

3 Department and Institute of Pathology, School of Pharmacy and Division of Laboratory Medicine in Sosnowiec, Medical University of Silesia, Katowice, ul. Ostrogórska 30, 41-200 Sosnowiec, Poland; E-Mails: rkubina@sum.edu.pl (R.K.); adzik@sum.edu.pl (A.K.-D.)

* Author to whom correspondence should be addressed; E-Mail: rwojtyczka@sum.edu.pl; Tel.: +48-32-364-16-21.

Received: 31 March 2014; in revised form: 18 May 2014 / Accepted: 19 May 2014 /

Published: 22 May 2014

\begin{abstract}
Synergistic interactions between commonly used antibiotics and natural bioactive compounds may exhibit therapeutic benefits in a clinical setting. Berberine, an isoquinoline-type alkaloid isolated from many kinds of medicinal plants, has proven efficacy against a broad spectrum of microorganisms. The aim of the presented work was to assess the antibacterial activity of berberine chloride in light of the effect exerted by common antibiotics on fourteen reference strains of Staphylococccus spp., and to evaluate the magnitude of interactions of berberine with these antistaphylococcal antibiotics. In our study minimum inhibitory concentrations (MIC) of berberine chloride against CoNS ranged from 16 to $512 \mu \mathrm{g} / \mathrm{mL}$. The most noticeable effects were observed for S. haemolyticus ATCC 29970, S. epidermidis ATCC 12228, S. capitis subsp. capitis ATCC 35661, S. galinarium ATCC 700401, S. hominis subsp. hominis ATCC 27844, S. intermedius ATCC 29663 and S. lugdunensis ATCC 49576. The most significant synergistic effect was noticed for berberine in combination with linezolid, cefoxitin and erythromycin. The
\end{abstract}


synergy between berberine and antibiotics demonstrates the potential application of compound combinations as an efficient, novel therapeutic tool for antibiotic-resistant bacterial infections.

Keywords: antimicrobial activity; coagulase-negative staphylococci (CoNS); berberine

\section{Introduction}

The widespread abuse of antibiotics for the treatment of bacterial infections has led to the emergence and spread of drug resistant strains. The rise in the rate of infections from multi-drug resistant (MDR) bacteria is recognized worldwide as a major health crisis. A recent joint technical report of the European Centre for Disease Prevention and Control (ECDC) and the European Medicines Agency (EMA) in collaboration with Action on Antibiotic Resistance (ReAct) estimated that at least 25,000 patients die each year in the EU from infections due to multidrug resistant bacteria [1]. Antibiotic resistant staphylococci strains are the major public health concern since the bacteria can circulate in the environment without difficulty. Coagulase-negative staphylococci (CoNS) colonize different parts of the human skin and mucous membranes. Notably, every species of CoNS that has been characterized as a resident in humans ( $S$. epidermidis, S. capitis, S. cohnii, S. haemolyticus, $S$. hominis, S. lugdunensis, S. saccharolyticus, S. saprophyticus, S.warneri), may also be responsible for nosocomial infections, particularly in immunocompromised patients. What is more, CoNS have become the leading cause of infections related to medical devices such as vascular catheters, prosthetic joints and artificial heart valves [2,3].

Plants are known to produce a variety of compounds as defenses against a wide range of microorganisms. Berberine is an isoquinoline-type alkaloid isolated from many kinds of medicinal plants such as Berberis aristata, Berberis aquifolium, Berberis vulgaris, Coptis chinensis, Coptis japonica, Hydrastis canadensis, Phellodendron amurense, Phellodendron chinense schneid and other species [4-6]. Berberine has antidiabetic, antidiarrhoeal, antimicrobial, immuno-stimulating, hypotensive and anti-inflammatory properties [4-8]. To evaluate its antibacterial activity, most studies have focused on the bacteriostatic and/or bactericidal activities of berberine toward different bacterial species $[9,10]$. It has been reported that berberine has weak activity against Gram-negative bacteria and is more active against Gram-positive bacteria including S. aureus and S. epidermidis [7]. Moreover, the toxicity and mutagenicity of berberine to human cells were relatively low in both in vitro and in vivo experiments. [8,11,12]. To our knowledge, isoquinoline-type alkaloids have not yet been investigated in the context of their possible synergistic effects with commonly used antibiotics against CoNS strains.

It has been shown that pharmacological treatment by some phytochemicals is an inexpensive, readily applicable approach in the chemotherapy and management of various infections $[5,6,8]$. Due to the multi-drug resistance problem the use of combinations of antibiotics with the different mechanisms of action is often necessary for the treatment of severe staphylococcal infections. The augmented action of antibiotics along with natural substances may have positive synergistic effects toward specific, drug resistant microorganisms which are difficult to eradicate, particularly in hospital settings. 
In this paper, we explored in vitro antimicrobial activity of berberine in combination with 10 different antibiotics (penicillin - P, erythromycin - E, clindamycin - DA, cefoxitin - FOX, ciprofloxacin - CIP, tobramycin-TOB, chloramphenicol-C, linezolid-LIN, tetracycline-TE, trimethoprim with sulfamethoxazole-SXT) against 14 reference strains of Staphylococccus spp. using minimum inhibitory concentration (MIC) and time-kill assays. All these antibiotics have been reported as antistaphylococcal drugs with different target points.

\section{Results and Discussion}

\subsection{Activity of the Berberine}

The antibacterial activity of berberine against the tested CoNS strains varied, with MIC values that ranged from 16 to $512 \mu \mathrm{g} / \mathrm{mL}$ (median $126 \mu \mathrm{g} / \mathrm{mL}$, Table 1). The highest MIC values were $16 \mu \mathrm{g} / \mathrm{mL}$ for $S$. capitis subsp. capitis and $32 \mu \mathrm{g} / \mathrm{mL}$ for $S$. epidermidis ATCC 12228. In case of 9 examined strains MIC values were within the range from $64 \mu \mathrm{g} / \mathrm{mL}$ to $128 \mu \mathrm{g} / \mathrm{mL}$. The lowest MIC values were observed for S. warneri ATCC 49454 strain $(512 \mu \mathrm{g} / \mathrm{mL})$, S. saprophyticus ATCC $15303(512 \mu \mathrm{g} / \mathrm{mL})$ and S. haemolyticus ATCC 29970 strain $(256 \mu \mathrm{g} / \mathrm{mL})$. Comparison of non-biofilm forming strain of S. epidermidis (ATCC 12228) and biofilm-forming strain (ATCC 35983), showed that the first one mentioned strain was four times less susceptible to berberine, with MIC values obtained as $32 \mu \mathrm{g} / \mathrm{mL}$ and $128 \mu \mathrm{g} / \mathrm{mL}$ respectively.

The berberine used in this study significantly inhibited the growth of all examined bacterial strains.

Table 1. MIC (expressed in $\mu \mathrm{g} / \mathrm{mL}$ ) of berberine against fourteen CoNS strains.

\begin{tabular}{lc}
\hline \multicolumn{1}{c}{ Bacterial strain } & MIC $(\boldsymbol{\mu g} / \mathbf{m L})$ \\
\hline S. epidermidis ATCC 12228 & 32 \\
S. epidermidis ATCC 35983 & 128 \\
S. haemolyticus ATCC 29970 & 256 \\
S. hominis subsp. hominis ATCC 27844 & 64 \\
S. warneri ATCC 49454 & 512 \\
S. saprophyticus ATTC 15303 & 512 \\
S. capitis subsp. capitis ATCC 35661 & 16 \\
S. intermedius ATCC29663 & 64 \\
S. lentus ATCC 700403 & 64 \\
S. lugdunensis ATCC 49576 & 64 \\
S. simulans ATCC 27851 & 128 \\
S. galinarium ATCC 700401 & 128 \\
S. sciuri ATCC 29060 & 128 \\
S. xylosus ATCC 700404 & 128 \\
\hline
\end{tabular}

\subsection{Time-Kill Assay}

After $2 \mathrm{~h}$ of incubation no growth of the tested strains was detected, both with and without berberine addition to the medium (Figure 1B). There were no differences between culture growth when comparing time-kill curves for different experiment starting points (Figure 1A). After $6 \mathrm{~h}$ of incubation we noted for all CoNS strains a substantial decrease of the number of microorganisms (evidenced by OD value changes) when compared to growth control (GC, Figure 1C). In the 12 th $\mathrm{h}$ of the study 
(Figure 1D) we observed an essential decrease of the number of microorganisms related to the berberine concentration within the range from $8 \mu \mathrm{g} / \mathrm{mL}$ to $512 \mu \mathrm{g} / \mathrm{m}$. After $24 \mathrm{~h}$ of experiment (Figure 1E) within the range of berberine concentrations from $32 \mu \mathrm{g} / \mathrm{mL}$ to $512 \mu \mathrm{g} / \mathrm{mL}$, a total growth inhibition was recorded for some strains, and no change of OD values was observed. The data obtained for $S$. warneri ATCC49454 strain showed that for all tested berberine concentrations, only small reduction of bacteria growth was observed, which may indicate an obvious strain resistance to berberine. In the case of the biofilm-forming strain $S$. epidermidis ATCC35983, a significant reduction of microorganism growth was observed for the first $12 \mathrm{~h}$, but after $24 \mathrm{~h}$ of incubation we detected a subsequent increase of the OD value apparently related to the biofilm formation phenomenon. However, even for this non-biofilm forming strain a reduction of the number of microorganisms, expressed as an OD change, was noticeable.

Figure 1. Growth kinetics of Staphylococcus strains in the presence of different berberine concentrations after $0 \mathrm{~h}$ of incubation (A); after $2 \mathrm{~h}$ of incubation (B); after $6 \mathrm{~h}$ of incubation (C); after $12 \mathrm{~h}$ of incubation (D) and after $24 \mathrm{~h}$ of incubation (E).

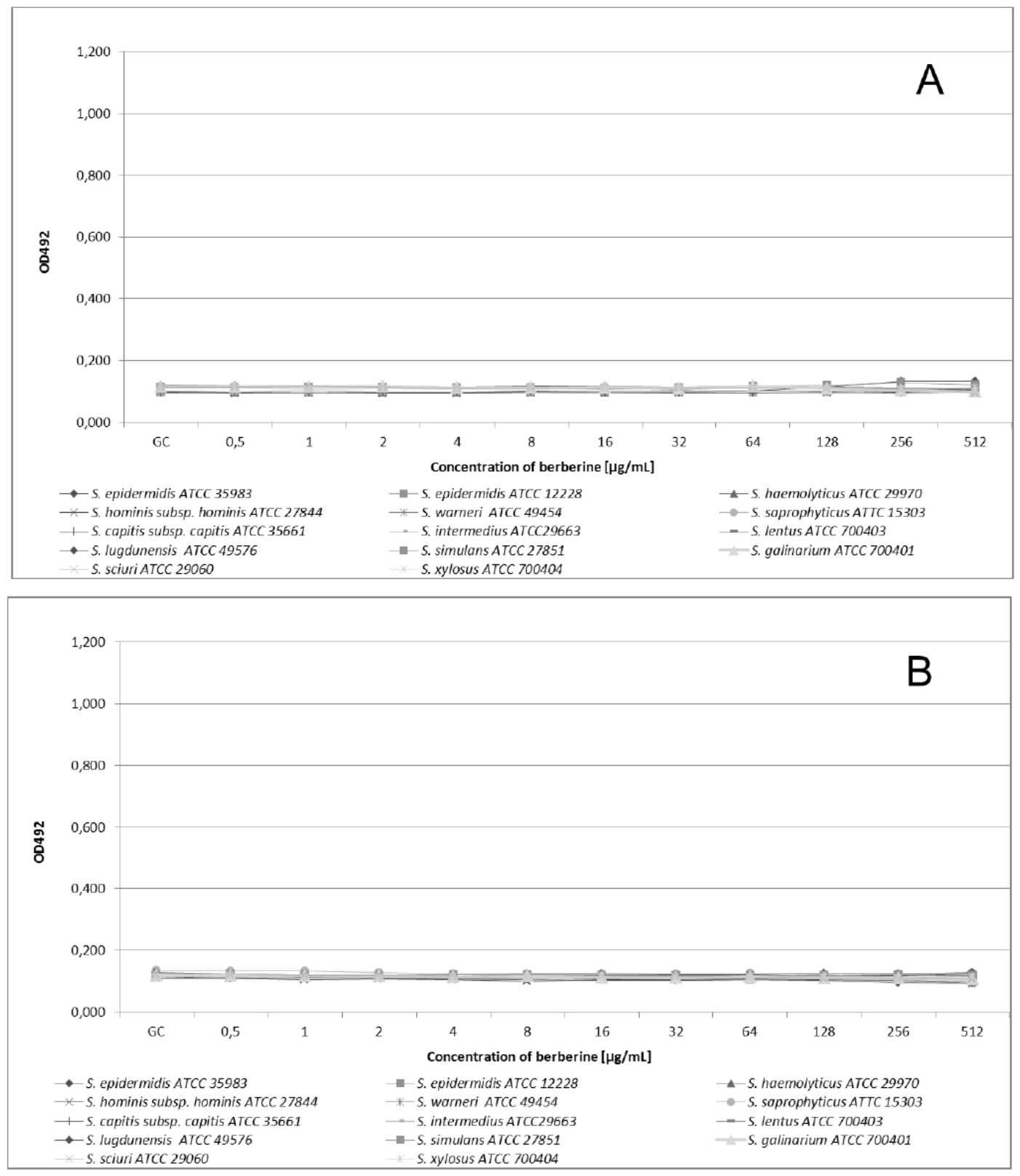


Figure 1. Cont.
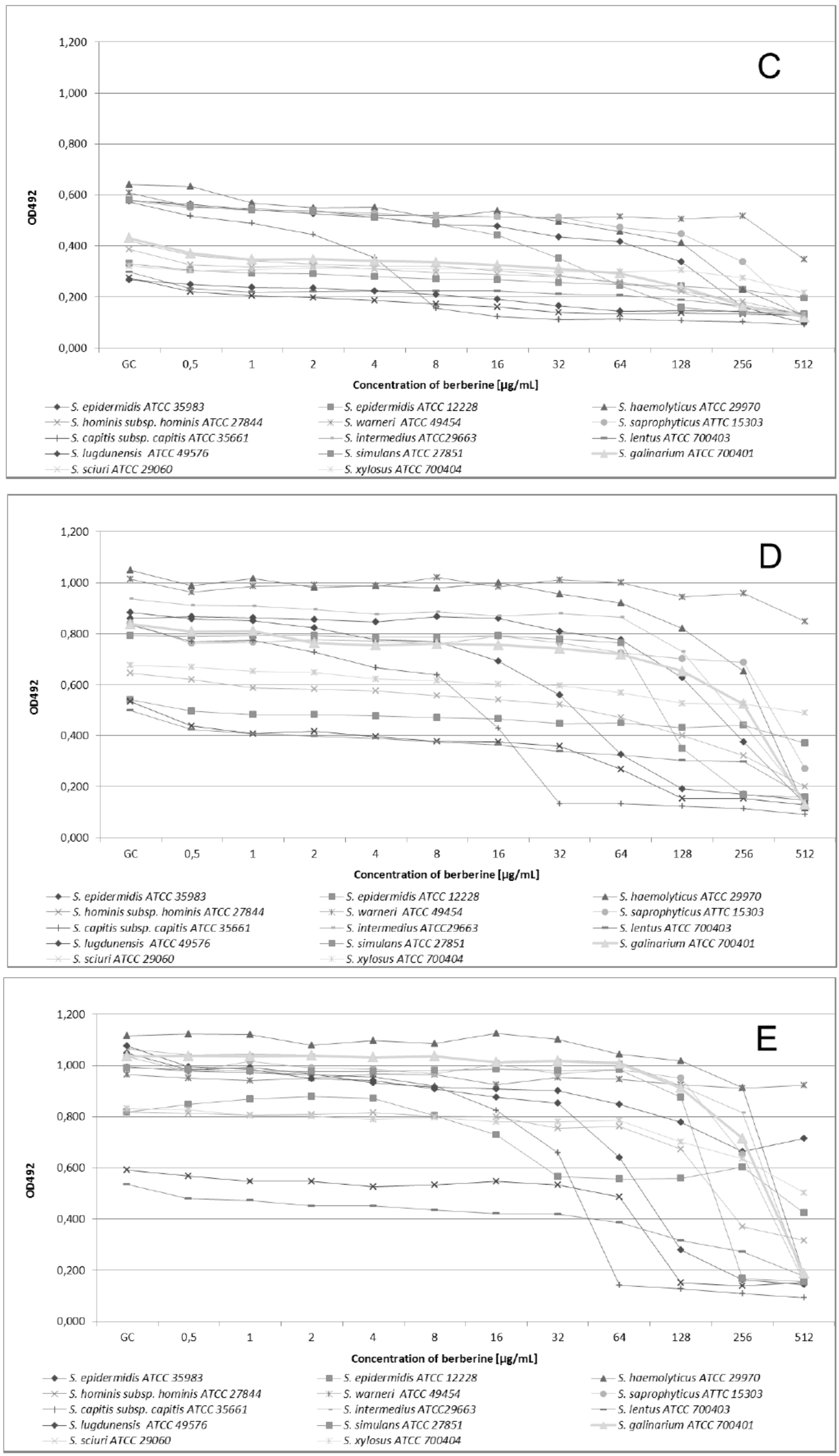
The ANOVA indicated that the growth kinetics of all staphylococcal strains was significantly affected by berberine incubation time $(p<0.001)$, type of strains $(p<0.001)$, interaction between strain and incubation time and concentration. The interaction between these factors was also significant $(p<0.001)$. The incubation time effect $(68.35 \%)$, type of strain $(7.43 \%)$, interaction between type of strain and incubation time (6.93\%) and concentration $(6.03 \%)$ explained most of variance (Table 2).

Table 2. Multivariate analysis of variance by three-way ANOVA of CoNS susceptibility to berberine.

\begin{tabular}{ccccccc}
\hline Factors & df & $\begin{array}{c}\text { Sum of } \\
\text { Squares }\end{array}$ & $\begin{array}{c}\text { Mean } \\
\text { Squares }\end{array}$ & F & $\begin{array}{c}\text { \% of } \\
\text { Variance }\end{array}$ & $\boldsymbol{p}$ \\
\hline strain (S) & 13 & 26.8035 & 2.0618 & 6016 & 7.43 & $<0.001$ \\
time (T) & 4 & 246.5799 & 61.6450 & 179878 & 68.35 & $<0.001$ \\
concentration (C) & 11 & 21.7349 & 1.9759 & 5766 & 6.03 & $<0.001$ \\
SxT & 52 & 24.9890 & 0.4806 & 1402 & 6.93 & $<0.001$ \\
SxC & 143 & 8.8737 & 0.0621 & 181 & 2.46 & $<0.001$ \\
TxC & 44 & 17.4305 & 0.3961 & 1156 & 4.83 & $<0.001$ \\
SxTxC & 572 & 13.4642 & 0.0235 & 69 & 3.73 & $<0.001$ \\
\hline
\end{tabular}

\subsection{Effects of Combinations of Berberine and Antibiotics against CoNS}

A combined effect of berberine and antibiotics was observed for seven out of 14 tested CoNS strains. A significant increase of the growth inhibition zone by more than $5 \mathrm{~mm}$ was observed around antibiotic discs after the addition of $1 / 4$ MIC berberine into the MHA medium (Wilcoxon Signed-Rank Test $p \leq 0.05$, Table 3 ). We did not observe any antagonistic interaction for any antibiotic-berberine combination studied.

The biggest differences in growth inhibition zone were observed for six of the investigated CoNS strains. An increase of the growth inhibition zone ranging from 9 to $18 \mathrm{~mm}$ was observed for the S. haemolyticus ATCC29970 strain following the addition of $1 / 4$ MIC berberine into the MHA medium. The greatest differences of growth inhibition zone size were observed for TE (increase from 30 to $48 \mathrm{~mm}$ ), LIN (increase from 31 to $45 \mathrm{~mm}$ ), TOB (increase from 26 to $40 \mathrm{~mm}$ ), C (increase from 27 to $41 \mathrm{~mm}$ ), FOX (increase from 33 to $47 \mathrm{~mm}$ ), P (increase from 33 to $46 \mathrm{~mm}$ ) and DA (increase from 26 to $37 \mathrm{~mm}$ ). For the above antibiotics we observed a substantial enhancement of the growth inhibition zone from 11 to $18 \mathrm{~mm}$.

In the case of the $S$. epidermidis ATCC12228 strain, the increase of the growth inhibition zone after addition of $1 / 4$ MIC berberine into MHA medium ranged from 2 to $14 \mathrm{~mm}$ (excluding CIP). The biggest differences in the size of the inhibited growth zones were seen for E (increase from 27 to $41 \mathrm{~mm}$ ), TOB (increase from 21 to $47 \mathrm{~mm}$ ), C (increase from 28 to $39 \mathrm{~mm}$ ), LIN (increase from 34 to $44 \mathrm{~mm}$ ), P (increase from 12 to $22 \mathrm{~mm}$ ), TE (increase from 1 to $9 \mathrm{~mm}$ ) and for DA (increase from 27 to $35 \mathrm{~mm}$ ). For these antibiotics, the growth inhibition zone increase ranged between 8 to $14 \mathrm{~mm}$. 
Table 3. The combined antimicrobial effect of antibiotics and berberine towards the reference CoNS staphylococci (mean inhibition growth zones in mm. Values are considered significant at $p \leq 0.05$ ).

\begin{tabular}{|c|c|c|c|c|c|c|c|c|c|c|c|c|c|c|c|c|c|c|c|c|}
\hline Strain & $\mathbf{P}$ & $\begin{array}{c}\mathbf{P} \\
+ \text { be }\end{array}$ & $\mathbf{E}$ & $\begin{array}{c}\mathbf{E} \\
+\mathbf{b e}\end{array}$ & DA & $\begin{array}{l}\text { DA } \\
+ \text { be }\end{array}$ & FOX & $\begin{array}{l}\text { FOX } \\
\text { +be }\end{array}$ & CIP & $\begin{array}{l}\text { CIP } \\
+ \text { be }\end{array}$ & ТОВ & $\begin{array}{l}\text { TOB } \\
+ \text { be }\end{array}$ & $\mathbf{C}$ & $\begin{array}{c}\text { C } \\
+ \text { be }\end{array}$ & LIN & $\begin{array}{l}\text { LIN } \\
+ \text { be }\end{array}$ & TE & $\begin{array}{r}\text { TE } \\
+ \text { be }\end{array}$ & SXT & $\begin{array}{l}\text { SXT } \\
+ \text { be }\end{array}$ \\
\hline $\begin{array}{l}\text { S. epidermidis } \\
\text { ATCC } 35983\end{array}$ & 0 & 0 & 0 & 0 & 0 & 0 & $12 \pm 2$ & $18 \pm 2$ & $30 \pm 2$ & $32 \pm 2$ & 17 & $18 \pm 2$ & $23 \pm 2$ & $26 \pm 2$ & $30 \pm 3$ & $33 \pm 1$ & $27 \pm 1$ & $29 \pm 1$ & $29 \pm 1$ & $31 \pm 1$ \\
\hline $\begin{array}{l}\text { S. epidermidis } \\
\text { ATCC } 12228\end{array}$ & $12 \pm 2$ & $22 \pm 1$ & $27 \pm 1$ & $41 \pm 1$ & $27 \pm 1$ & $35 \pm 1$ & $34 \pm 3$ & $36 \pm 2$ & $28 \pm 1$ & $27 \pm 1$ & $27 \pm 2$ & $41 \pm 1$ & $28 \pm 1$ & $39 \pm 1$ & $33 \pm 2$ & $44 \pm 2$ & 0 & $9 \pm 3$ & $23 \pm 2$ & $23 \pm 2$ \\
\hline $\begin{array}{l}\text { S. haemolyticus } \\
\text { ATCC } 29970\end{array}$ & $33 \pm 1$ & $46 \pm 2$ & $26 \pm 2$ & $35 \pm 3$ & $26 \pm 1$ & $37 \pm 1$ & $33 \pm 1$ & $47 \pm 3$ & $30 \pm 1$ & $39 \pm 1$ & $26 \pm 1$ & $40 \pm 1$ & $27 \pm 1$ & $41 \pm 3$ & $31 \pm 2$ & $45 \pm 1$ & $30 \pm 1$ & $48 \pm 2$ & 22 & 40 \\
\hline $\begin{array}{l}\text { S. hominis subsp. } \\
\text { hominis ATCC } 27844\end{array}$ & $34 \pm 2$ & $38 \pm 1$ & $34 \pm 2$ & 40 & $29 \pm 1$ & $34 \pm 2$ & 32 & $41 \pm 1$ & $31 \pm 2$ & $33 \pm 1$ & $27 \pm 1$ & $30 \pm 2$ & $30 \pm 2$ & $35 \pm 1$ & $34 \pm 3$ & $45 \pm 3$ & $11 \pm 1$ & $12 \pm 2$ & 32 & $33 \pm 1$ \\
\hline S. warneri ATCC49454 & $31 \pm 2$ & $31 \pm 3$ & $24 \pm 2$ & $26 \pm 1$ & $28 \pm 2$ & 28 & 32 & $37 \pm 1$ & $27 \pm 1$ & $30 \pm 2$ & $25 \pm 1$ & 26 & $26 \pm 2$ & $29 \pm 3$ & $31 \pm 2$ & $33 \pm 2$ & $31 \pm 3$ & $33 \pm 1$ & $31 \pm 1$ & $33 \pm 2$ \\
\hline $\begin{array}{l}\text { S. saprophyticus } \\
\text { ATTC15303 }\end{array}$ & $27 \pm 1$ & 29 & $29 \pm 1$ & $32 \pm 1$ & 28 & $33 \pm 1$ & $31 \pm 1$ & $32 \pm 1$ & $27 \pm 1$ & 28 & $28 \pm 1$ & $32 \pm 1$ & $28 \pm 2$ & $29 \pm 1$ & $33 \pm 2$ & $36 \pm 1$ & $32 \pm 2$ & $37 \pm 2$ & $32 \pm 2$ & $33 \pm 1$ \\
\hline $\begin{array}{l}\text { S. capitis subsp. capitis } \\
\text { ATCC } 35661\end{array}$ & $32 \pm 3$ & $35 \pm 2$ & $24 \pm 1$ & $31 \pm 1$ & $29 \pm 1$ & $31 \pm 1$ & $31 \pm 1$ & $36 \pm 1$ & $29 \pm 1$ & $32 \pm 2$ & $27 \pm 1$ & $33 \pm 1$ & $30 \pm 1$ & $38 \pm 2$ & $32 \pm 2$ & $37 \pm 1$ & $33 \pm 2$ & $37 \pm 2$ & $31 \pm 2$ & $36 \pm 2$ \\
\hline $\begin{array}{l}\text { S. intermedius } \\
\text { ATCC } 29663\end{array}$ & $38 \pm 2$ & $42 \pm 2$ & $29 \pm 1$ & $35 \pm 2$ & $30 \pm 3$ & $32 \pm 2$ & $35 \pm 1$ & $37 \pm 1$ & $30 \pm 2$ & $31 \pm 3$ & $27 \pm 1$ & $29 \pm 1$ & $28 \pm 1$ & $31 \pm 1$ & $31 \pm 1$ & $34 \pm 1$ & $33 \pm 1$ & $36 \pm 1$ & $28 \pm 1$ & $32 \pm 2$ \\
\hline S. lentus ATCC700403 & $24 \pm 1$ & $30 \pm 3$ & $25 \pm 1$ & $27 \pm 1$ & $22 \pm 2$ & $23 \pm 1$ & 34 & $39 \pm 2$ & $28 \pm 2$ & $27 \pm 3$ & $23 \pm 3$ & $25 \pm 2$ & $30 \pm 1$ & $30 \pm 3$ & $33 \pm 1$ & $35 \pm 2$ & $27 \pm 2$ & $31 \pm 1$ & $26 \pm 2$ & $28 \pm 3$ \\
\hline $\begin{array}{l}\text { S. lugdunensis } \\
\text { ATCC49576 }\end{array}$ & $12 \pm 1$ & $15 \pm 1$ & $29 \pm 1$ & $33 \pm 3$ & $29 \pm 2$ & $33 \pm 2$ & $35 \pm 2$ & $38 \pm 2$ & $31 \pm 3$ & $34 \pm 3$ & $24 \pm 2$ & $30 \pm 2$ & $28 \pm 2$ & $29 \pm 2$ & $30 \pm 1$ & $33 \pm 1$ & $33 \pm 1$ & $37 \pm 1$ & $28 \pm 2$ & $30 \pm 1$ \\
\hline $\begin{array}{l}\text { S. simulans } \\
\text { ATCC27851 }\end{array}$ & $19 \pm 3$ & $21 \pm 3$ & $31 \pm 1$ & $35 \pm 1$ & $31 \pm 1$ & $36 \pm 3$ & $36 \pm 3$ & $37 \pm 2$ & 36 & $37 \pm 1$ & $29 \pm 2$ & $31 \pm 3$ & $29 \pm 1$ & $33 \pm 3$ & $32 \pm 1$ & $36 \pm 2$ & 12 & $16 \pm 1$ & $28 \pm 2$ & $27 \pm 1$ \\
\hline $\begin{array}{l}\text { S. galinarium } \\
\text { ATCC700401 }\end{array}$ & 9 & $13 \pm 1$ & $25 \pm 1$ & $33 \pm 1$ & $21 \pm 1$ & $27 \pm 1$ & $20 \pm 1$ & $27 \pm 1$ & $27 \pm 1$ & $30 \pm 0$ & $24 \pm 1$ & $30 \pm 2$ & $26 \pm 1$ & $31 \pm 1$ & $29 \pm 1$ & $34 \pm 2$ & $9 \pm 1$ & $11 \pm 1$ & $27 \pm 1$ & $27 \pm 1$ \\
\hline S.sciuri ATCC29060 & $24 \pm 1$ & $27 \pm 2$ & $24 \pm 1$ & 27 & $24 \pm 1$ & $26 \pm 1$ & 28 & $32 \pm 2$ & $26 \pm 1$ & $26 \pm 1$ & $22 \pm 1$ & $24 \pm 1$ & $26 \pm 1$ & $29 \pm 1$ & $30 \pm 1$ & $33 \pm 1$ & $27 \pm 1$ & $31 \pm 1$ & $23 \pm 1$ & $23 \pm 1$ \\
\hline S. xylosus ATCC700404 & $9 \pm 2$ & $12 \pm 1$ & 0 & 0 & 0 & 0 & $37 \pm 1$ & $39 \pm 1$ & $30 \pm 1$ & $30 \pm 2$ & $19 \pm 1$ & $20 \pm 1$ & $28 \pm 2$ & $30 \pm 2$ & $32 \pm 1$ & $35 \pm 1$ & $14 \pm 1$ & $16 \pm 1$ & $32 \pm 2$ & $32 \pm 2$ \\
\hline average & $22 \pm 1$ & $26 \pm 1$ & $23 \pm 1$ & $28 \pm 1$ & $23 \pm 1$ & $27 \pm 1$ & $31 \pm 1$ & $36 \pm 2$ & $29 \pm 1$ & $31 \pm 1$ & $25 \pm 1$ & $29 \pm 1$ & $28 \pm 1$ & $32 \pm 2$ & $32 \pm 2$ & $37 \pm 1$ & $23 \pm 1$ & $27 \pm 1$ & $28 \pm 1$ & $31 \pm 1$ \\
\hline
\end{tabular}


Inhibition growth enhancement of $S$. capitis subsp. capitis ATCC35661 from 3 to $8 \mathrm{~mm}$ after addition of berberine to the MHA medium was observed. The most noticeable differences in size of the growth inhibition zone were found in the presence of $\mathrm{E}$ (increase from 24 to $31 \mathrm{~mm}$ ), C (increase from 30 to $38 \mathrm{~mm}$ ) and TOB (increase from 27 to $33 \mathrm{~mm}$ ). These antibiotics showed a growth inhibition zone increase from 6 to $8 \mathrm{~mm}$.

The effect of the interaction of berberine and antibiotics on $S$. galinarium ATCC700401 strain was expressed as the increase of inhibition growth zone by 3-8 $\mathrm{mm}$. The biggest differences in the growth inhibition zones sizes were observed in case of $\mathrm{E}$ (increase from 25 to $33 \mathrm{~mm}$ ), FOX (increase from 20 to $27 \mathrm{~mm}$ ), TOB (increase from 24 to $30 \mathrm{~mm}$ ) and DA (increase from 21 to $27 \mathrm{~mm}$ ). For these antibiotics we noticed an increase of the inhibition zone ranging from 6 to $8 \mathrm{~mm}$.

The increase of growth inhibition zones for S. hominis subsp. hominis ATCC27844 strain were between 1 to $11 \mathrm{~mm}$. The biggest differences in inhibition zone growth were noted for LIN (increase from 34 to $45 \mathrm{~mm}$ ), FOX (increase from 32 to $41 \mathrm{~mm}$ ) and $\mathrm{E}$ (increase from 34 to $40 \mathrm{~mm}$ ). For these antibiotics the most significant growth inhibition zones were within the range from 6 to $11 \mathrm{~mm}$.

An increase of the growth inhibition zone within the range from 1 to $6 \mathrm{~mm}$ was observed for S. lugdunensis ATCC49576 strain. The greatest differences in growth inhibition zones were observed for TOB (increase from 24 to $30 \mathrm{~mm}$ ), for which the increase of the growth inhibition zone was $6 \mathrm{~mm}$.

For other investigated strains increases of growth inhibition zone of more than $5 \mathrm{~mm}$ were observed for FOX and S. epidermidis ATCC35983 (increase from 12 to $18 \mathrm{~mm}$ ) and for $\mathrm{P}$ and $S$. lentus ATCC700403 (increase from 24 to $30 \mathrm{~mm}$ ).

Our analysis of the influence of berberine on the antimicrobial action of the selected antibiotics, revealed an increase of the growth inhibition zone in the presence of berberine at a concentration corresponding to $1 / 4 \mathrm{MIC}$ for all examined strains. The most susceptible strains towards berberine were S. haemolyticus ATCC29970, S. epidermidis ATCC 12228, S. capitis subsp. capitis ATCC35661, S. galinarium ATCC700401, S. hominis subsp. hominis ATCC27844, S. intermedius ATCC29663, and also $S$. lugdunensis ATCC49576. Assessing the other investigated strains, such as $S$. sciuri ATCC29060, S. epidermidis ATCC35983, S. saprophyticus ATCC15303, S. simulans ATCC27851, S. xylosus ATCC700404, S. warneri ATCC49454 and S. lentus ATCC700403, the enhancement of growth inhibition following addition of berberine to MHA was observed only to a minor extent, up to $5 \mathrm{~mm}$. The weakest interactions between berberine and anti-staphylococcal drugs was found for $S$. xylous ATCC70040, S. warneri ATCC49454, and S. lentus ATCC700403.

The most significant synergistic effect was noticed for berberine in combination with LIN, FOX and E (Table 4). For all tested strains the combination of berberine and STX resulted in the appearance of a double growth inhibition zone along with a clear reduction of the microorganisms within the first inhibitory zone.

Berberine is an isoquinoline-type alkaloid isolated from many herbs. It has been reported that berberine shows relatively weak antimicrobial activity against Gram-negative bacteria and is more effective against Gram-positive ones [7,13]. The empirical multidrug antimicrobial therapy is usually applied to expand the antibacterial spectrum and reduce the selection of drug resistant mutants. In addition, combinations of different antimicrobial agents that exhibit synergy or partial synergy, may augment the antimicrobial effect in patients with persistent infections at lower concentrations. The application of antibiotics supported by bioactive substances originating from natural products seems to 
be a promising and efficient therapy for such infections. This can suggest a potential role of berberine as a supportive compound which may play a significant role in the reduction of adverse effects which are frequently caused by common antibiotics [14].

Table 4. Alteration of inhibition growth zone investigated antibiotics in combination with berberine for CoNS strains. Pearson Correlation $p=0.97$.

\begin{tabular}{cccc}
\hline & $\begin{array}{c}\text { Antibiotic } \\
\text { (Inhibition Growth Zone in } \mathbf{~ m m} \pm \mathbf{S D} \text { ) }\end{array}$ & $\begin{array}{c}\text { Antibiotic with Berberine } \\
\text { (Inhibition Growth Zone in } \mathbf{~ m m} \pm \mathbf{S D} \text { ) }\end{array}$ & Pearson Correlation \\
\hline LIN & $32 \pm 2$ & $37 \pm 1$ & $\mathrm{r}=0.62$ \\
FOX & $31 \pm 1$ & $36 \pm 2$ & $\mathrm{r}=0.86$ \\
E & $23 \pm 1$ & $28 \pm 1$ & $\mathrm{r}=0.97$ \\
P & $22 \pm 1$ & $26 \pm 1$ & $\mathrm{r}=0.93$ \\
DA & $23 \pm 1$ & $27 \pm 1$ & $\mathrm{r}=0.97$ \\
TOB & $25 \pm 1$ & $29 \pm 1$ & $\mathrm{r}=0.77$ \\
C & $28 \pm 1$ & $32 \pm 2$ & $\mathrm{r}=0.42$ \\
TE & $23 \pm 1$ & $27 \pm 1$ & $\mathrm{r}=0.94$ \\
CIP & $29 \pm 1$ & $31 \pm 1$ & $\mathrm{r}=0.73$ \\
STX & $28 \pm 1$ & $31 \pm 1$ & $\mathrm{r}=0.34$ \\
\hline
\end{tabular}

The majority of research focusing on the antibacterial effects of berberine are related to its influence on $S$. aureus strains $[9,15,16]$, and the combined synergistic effect of berberine along with the selected antibiotics towards $S$. aureus and $S$. epidermidis strains $[10,13,17,18]$. According to previous reports, both $S$. aureus strains and CoNS strains were found to show a highly variable susceptibility to antibiotics and natural products [19,20].

To the best our knowledge the presented work seems to be a pioneering study focused on the biological effect of berberine alone and in combination with the selected antibiotics on coagulasenegative staphylococci other than S. epidermidis. A study of the anti-staphylococcal activity of berberine on MRSA strains, carried out by Yu et al. [13], indicated a significantly higher susceptibility of these strains to berberine, compared to the CoNS strains included in our study, with MIC values ranging from $32 \mu \mathrm{g} / \mathrm{mL}$ to $128 \mu \mathrm{g} / \mathrm{mL}$. Similar results were presented by Zuo et al. [17] who assessed MIC values for berberine and for 10 MRSA strains. In our study the MIC of berberine chloride against 14 CoNS strains ranged widely from 16 to more than $512 \mu \mathrm{g} / \mathrm{mL}$. These MIC values are compared with data presented by $\mathrm{Yu}$ et al. and Zuo et al. which suggests that some CoNS strains may show higher resistance against berberine derivatives than MRSA strains.

In our study, the MIC values for biofilm-forming $S$. epidermidis were four times higher than for a non-biofilm forming strain (ATCC12228). A similar effect was also observed by Wang et al. [21] who performed a comparative investigation of the use of berberine using three reference $S$. epidermidis strains (two biofilm-forming and one non-biofilm forming) in a microbiological assessment of berberine activity on $S$ epidermidis strains. The MIC values were $256 \mu \mathrm{g} / \mathrm{mL}, 128 \mu \mathrm{g} / \mathrm{mL}$, and $64 \mu \mathrm{g} / \mathrm{mL}$. These studies indicate a preventative role of berberine on the biofilm formation ability of $S$. epidermidis.

There are very few reports addressing the combined effects of active, natural substances such as baicalein and ciprofloxacin [22], ethanol extract of propolis and anti-staphylococcal drugs [20], flavones 
and $\beta$-lactam antibiotics [23], berberine and ampicillin or oxacillin [13] berberine and ampicillin, azithromycin, cefazolin or levofloxacin [17] towards S. aureus strains. Reports about the synergistic effects of different compounds on CoNS are rare, however they indicate the possibility of augmenting the antibacterial effect of commonly used antibiotics by adding certain natural compounds.

The results obtained suggest that berberine possesses substantial antimicrobial activity toward CoNS, and indicate that the combination of berberine with oxazolidiones (LIN), $\beta$-lactams (FOX), macrolides (E) and another antibiotics results in a synergistic reaction. The interaction of berberine with different antimicrobial agents might be attributed to a blockage of different bacterial resistance mechanisms, including the bacterial efflux pump inhibitory effect of berberine compounds [24,25]. A model of the synergistic mechanism of berberine and antibiotics is hypothetically based on blocking the NorA pump and potentiating the antibiotics' action. Berberine, which accumulates in the cell, driven by the membrane potential may prevent the NorA pump from extruding some antibiotics [26,27]. According to previous reports by Jin et al. the mechanisms for the bactericidal effect of berberine may include inhibition of DNA replication, RNA transcription, and protein biosynthesis, influence or inhibition of enzyme activities, and destruction of the bacterial cell surface structure resulting in $\mathrm{Ca}^{2+}$ and $\mathrm{K}^{+}$release from cells [9]. This synergistic effect of antibiotics along with berberine may have potential practical application in a clinical environment as a efficient measure for eradicating infectious CoNS strains, in cases requiring a non-standard pharmacological approach.

\section{Experimental}

\subsection{Bacterial Strains, Media and Reagents}

The antibacterial activity of berberine was assessed against fourteen CoNS standard strains: S. epidermidis ATCC12228, S. epidermidis ATCC35983 (biofilm positive), S. haemolyticus ATCC29970, S. hominis subsp. hominis ATCC27844, S. warneri ATCC49454, S. saprophyticus ATCC15303, S. capitis subsp. capitis ATCC35661, S. intermedius ATCC29663, S. lentus ATCC700403, S. lugdunensis ATCC49576, S. simulans ATCC27851, S. galinarium ATCC700401, S. sciuri ATCC29060 and S. xylosus ATCC700404. Bacterial strains were stored for further analyses in TSB (Tryptic Soy Broth) medium with $20 \%$ of glycerol at $-80{ }^{\circ} \mathrm{C}$ and used as required. Tryptic soy broth (TSB) and Mueller-Hinton Agar (MHA) were obtained from (BTL, Łódź, Poland). The berberine chloride $\left(\mathrm{C}_{20} \mathrm{H}_{18} \mathrm{ClNO}_{4}\right.$, molecular weight 371.81) used in this study was obtained from Sigma Chemical Co. (St. Louis, MO, USA) Berberine was dissolved in deionized water and filtered through a $0.22 \mu \mathrm{m}$ Millipore filter (Sartorius Co. Bohemia, NY, USA) before use.

\subsection{Microdilution Method}

The MICs of berberine were determined by a microtitre broth dilution method. Growth inhibition assays were performed in sterile 96-well plates (FL Medical, Torreglia, Italy) in a final volume of $200 \mu \mathrm{L}[28,29]$. The cell concentrations were estimated from the optical densities at $600 \mathrm{~nm}$ wavelength with the formula $\mathrm{CFU} / \mathrm{mL}=A_{600}\left(3.8 \times 10^{8}\right)$, where $\mathrm{CFU}$ was the number of colony-forming units. One hundred microliters of mid-logarithmic-phase bacterial cultures $\left(5 \times 10^{5} \mathrm{CFU} / \mathrm{mL}\right)$ in TSB was added to $100 \mu \mathrm{L}$ of serially diluted berberine $(0.5,1,2,4,8,16,32,64,128,256$, and $512 \mu \mathrm{g} / \mathrm{mL})$. Wells 
containing TSB with bacterial inoculum only served as the bacterial growth control (GC). Additional controls included TSB alone (medium sterility control), TSB with different concentrations of berberine and bacterial inoculum. All samples were prepared in triplicates. Microplates were incubated at $37{ }^{\circ} \mathrm{C}$ for 2, 6, 12 and $24 \mathrm{~h}$, and the bacterial cell growth was assessed by measuring the optical density of cultures at $600 \mathrm{~nm}$ wavelength with a Multiskan EX microplate reader (Thermo Electron Corp., Vantoa, Finland) [30,31]. MICs were defined as the lowest berberine concentration that yielded no visible growth after $24 \mathrm{~h}$ of incubation [28,29].

\subsection{Disk Diffusion Method}

All isolates were tested for antimicrobial susceptibility by the disk diffusion method-based analysis, using MHA and commercially available disks containing an antimicrobial agent according to the EUCAST recommendations [32]. For disk diffusion testing, $90 \mathrm{~mm}$ plates with the agar medium were inoculated by swabbing the agar with a swab soaked in a bacterial suspension of $1 \times 10^{8}$ cells $/ \mathrm{mL}$. Disks (EMAPOL, Gdańsk, Poland) containing penicillin (P) 1 IU, erythromycin (E) $15 \mu \mathrm{g}$, clindamycin (DA) $2 \mu \mathrm{g}$, cefoxitin (FOX) $30 \mu \mathrm{g}$, ciprofloxacin (CIP) $5 \mu \mathrm{g}$, tobramycin (TOB) $10 \mu \mathrm{g}$, chloramphenicol (C) $30 \mu \mathrm{g}$, linezolid (LIN) $10 \mu \mathrm{g}$, tetracycline (TE) $30 \mu \mathrm{g}$ or trimethoprim with sulfamethoxazole (SXT) $1.25+23.75 \mu \mathrm{g}$ were used for the analysis of antimicrobial susceptibility.

The combined effect of antibiotics and berberine was studied using plates with MHA plus one-fourth of the MIC of berberine, which was considered as a sub-inhibitory concentration [33,34]. Disks were placed onto an agar surface and gently pressed to ensure contact using sterile forceps. Plates were incubated at $35{ }^{\circ} \mathrm{C}$ for $20 \mathrm{~h}$ in air. The susceptibility testing of each antibiotic for each isolate and the reference strains was performed in triplicate. After the incubation period diameters of the growth inhibition zones (in $\mathrm{mm}$ ) were measured for each strain, and the mean values were calculated.

\subsection{Statistical Analyses}

To determine the percentage of the variation attributable to the factors such as bacterial strains, time, and concentrations the results concerning the bacterial growth were analyzed by a three-way analysis of variance (ANOVA). The results from synergism assay were submitted to the Wilcoxon Signed-Rank Test and Mann Whitney U Test comparing the values ( $\mathrm{mm}$ ) of the inhibitory zone in the disk diffusion method. The statistical analyses were performed using the Statistica 10.0 PL software package, assuming the statistical significance level of $p \leq 0.05$.

\section{Conclusions}

The antimicrobial effect of berberine chloride in combination with various anti-staphylococcal drugs on reference CoNS strains varied greatly depending on the bacterial strain and drug used. The most significant synergistic effects towards CoNS strains were noted when berberine was combined with linezolid, cefoxitin and erythromycin. Our data showed a synergy of berberine and antibiotics in the antimicrobial action against some reference CoNS strains in vitro, what seems to suggest a potential role of berberine as a compound capable of augmenting the action of common antibiotics in vivo. Future work is necessary to precisely assess the effects of berberine in the treatment of CoNS 
infections, which may result in the development of efficient new therapeutic strategies for persistent staphylococcal infections.

\section{Author Contributions}

Robert D. Wojtyczka and Arkadiusz Dziedzic conceived the study idea, designed the experiments, analyzed the data, and wrote the manuscript. Małgorzata Kępa, Danuta Idzik conceived the study idea, designed the experiments, and critically revised the manuscript. Agata Kabała-Dzik, Robert Kubina and Tomasz Mularz organized the data and revised the manuscript. All authors read and approved the final manuscript.

\section{Conflicts of Interest}

Authors declare no potential conflict of interest.

\section{References}

1. ECDC/EMEA Joint Technical Report: The bacterial challenge: Time to react. ECDC/EMEA: Stockholm, Sweden, 2009. Available online: http://www.ecdc.europa.eu/en/publications/ Publications/Forms/ECDC DispForm.aspx?ID=444 (accessed on 17 September 2009).

2. Vuong, C.; Otto, M. Staphylococcus epidermidis infections. Microbes Infect. 2002, 4, 481-489.

3. Kloos, W.; Schleifer, K.H. Staphylococcus. In Bergey's Manual of Systematic Bacteriology Sneath, P.H.A., Ed.; Williams \& Wilkins: Baltimore, MD, USA, 1986; Volume 2, pp. 1013-1035.

4. Imanshahidi, M.; Hosseinzadeh, H. Pharmacological and therapeutic effects of Berberis. vulgaris and its active constituent. Phytother. Res. 2008, 22, 999-1012.

5. Tillhon, M.; Guman Ortiz, L.M.; Lombardi, P.; Scovassi, A.I. Berberine: New perspectives for old remedies. Biochem. Pharmacol. 2012, 84, 1260-1267.

6. Singh, A.; Duggal, S.; Kaur, N.; Singh, J. Berberine: Alkaloid with wide spectrum of pharmacological activities. J. Nat. Prod. 2010, 3, 64-75.

7. Vuddanda, P.R.; Chakraborty, S.; Singh, S. Berberine: A potential phytochemical with multispectrum therapeutic activities. Expert Opin. Inv. Drug. 2010, 19, 1297-307.

8. Birdsall, T.C.; Kelly, G.S. Berberine: Therapeutic potential of an alkaloid found in several medicinal plants. Altern. Med. Rev. 1997, 2, 94-103.

9. Jin, J.L.; Hua G.G.; Meng, Z.; Gao, P.J. Antibacterial mechanisms of berberine and reasons for little resistance of bacteria. Chin. Herb. Med. 2010, 3, 27-35.

10. Čerňákowá, M.; Koštalová, D. Antimicrobial activity of berberine-a constituent of Mahonia. aquifolium. Folia Microbiol. 2002, 47, 375-378.

11. Mantena, S.K.; Sharma, S.D.; Katiyar, S.K. Berberine, a natural product, induces G1-phase cell cycle arrest and caspase-3-dependent apoptosis in humane prostate carcinoma cell. Mol. Cancer Ther. 2006, 5, 296-308.

12. Zeng, X.H.; Zeng, X.J.; Li, Y.Y. Efficacy and safety of berberine for congestive heart failure secondary to ischemic or idiopathic dilated cardiomyopathy. Am. J. Cardiol. 2003, 93, 173-176. 
13. Yu, H.H.; Kim, K.J.; Cha, J.D.; Kim, H.K.; Lee, Y.E.; Choi, N.Y.; You, Y.O. Antimicrobial activity of berberine alone and in combination with ampicillin or oxacillin against methicillinresistant Staphylococcus aureus. J. Med. Food 2005, 8, 454-461.

14. Song, W.; Woo, H.J.; Kim, J.S.; Lee, K.M. In vitro activity of $\beta$-lactams, in combination with other antimicrobial agents against resistant strains of Pseudomonas aeruginosa. Int. J. Antimicrobial Agents 2003, 21, 8-12.

15. Freilea, M.L.; Giannini, F.; Pucci, G.; Sturniolo, A.; Rodero, L.; Pucci, O.; Balzareti, V.; Enriz, R.D. Antimicrobial activity of aqueous extracts and of berberine isolated from Berberis. heterophylla. Fitoterapia 2003, 74, 602-705.

16. Li, A.R.; Zhu, Y.; Li, X.N.; Tian, X.J. Antimicrobial activity of four species of Berberidaceae. Fitoterapia 2007, 78, 379-381.

17. Zuo, G.Y.; Li, Y.; Han, J.; Wang, G.C.; Zhang, Y.L.; Bian, Z.Q. Antibacterial and synergy of berberines with antibacterial agents against clinical multi-drug resistant isolates of Methicillin-Resistant Staphylococcus aureus (MRSA). Molecules 2012, 17, 10322-10330.

18. Musumeci, R.; Speciale, A.; Costanzo, R.; Annino, A.; Ragusa, S.; Rapisarda, A.; Pappalardo M.S.; Iauk, L. Berberis aetnensis C. Presl. extracts: Antimicrobial properties and interaction with ciprofloxacin. Int. J. Antimicrobial Agents 2003, 22, 48-53.

19. Wojtyczka, R.D.; Kępa, M.; Idzik, D.; Kubina, R.; Kabała-Dzik, A.; Dziedzic, A.; Wąsik, T.J. In vitro antimicrobial activity of ethanolic extract of Polish propolis against biofilm forming Staphylococcus epidermidis strains. Evid-Based Complement. Alternat. Med. 2013, doi:10.1155/2013/590703.

20. Wojtyczka, R.D.; Dziedzic, A.; Idzik, D.; Kępa, M.; Kubina, R.; Kabała-Dzik, A.; Smoleń-Dzirba, J.; Stojko, J.; Sajewicz, M.; Wąsik, T.J. Susceptibility of Staphylococcus aureus clinical isolates to propolis extract alone or in combination with antimicrobial drugs. Molecules 2013, 18, 9623-9640.

21. Wang, X.; Yao, X.; Zhu, Z.; Tang, T.; Dai, K.; Sadovskaya, I.; Flahaut, S.; Jabbouri, S. Effect of berberine on Staphylococcus epidermidis biofilm formation. Int. J. Antimicrobial Agents 2009 , 34, 60-66.

22. Chan, B.C.; Ip, M.; Lau, C.B.; Lui, S.L.; Jolivalt, C.; Ganem-Elbaz, C.; Litaudon, M.; Reiner, N.E.; Gong, H.; See, R.H.; et al. Synergistic effects of baicalein with ciprofloxacin against NorA over-expressed methicillin-resistant Staphylococcus aureus (MRSA) and inhibition of MRSA pyruvate kinase. J. Ethnopharmacol. 2011, 137, 767-773.

23. Sato, Y.; Shibata, H.; Arai, T.; Yamamoto, A.; Okimura, Y.; Arakaki, N.; Higuti, T. Variation in synergistic activity by flavone and its related compounds on the increased susceptibility of various strains of methicillin-resistant Staphylococcus aureus to beta-lactam antibiotics. Int. J. Antimicrobial Agents 2004, 24, 226-233.

24. Petersen, P.J.; Labthavikul, P.; Jones, C.H.; Bradford, P.A. In vitro antibacterial activities of tigecycline in combination with other antimicrobial agents determined by chequerboard and time-kill kinetic analysis. J. Antimicrob. Chemother. 2006, 57, 573-576.

25. Wagner, H.; Ulrich-Merzenich, G. Synergy research: Approaching a new generation of phytopharmaceuticals. Phytomedicine 2009, 16, 97-110. 
26. Stermitz, F.R.; Lorenz, P.; Tawara J.N.; Zenewicz, L.A.; Lewis, K. Synergy in a medicinal plant: Antimicrobial action of berberine potentiated by 5 "-methoxyhydnocarpin, a multidrug pump inhibitor. Proc. Natl. Acad. Sci. USA 2000, 97, 1433-1437.

27. Ettefagh, K.A.; Burns J.T.; Junio H.A.; Kaatz G.W.; Cech N.B. Goldenseal (Hydrastis canadensis L.) extracts synergistically enhance the antibacterial activity of berberine via efflux pump inhibition. Planta Med. 2011, 77, 835-840.

28. Amsterdam, D. Susceptibility testing of antimicrobials in liquid media. In Antibiotics in Laboratory Medicine, 5th ed.; Loman, V., Ed.; Williams and Wilkins: Philadelphia, PA, USA, 2005; pp. 61-143.

29. European Committee for Antimicrobial Susceptibility Testing (EUCAST) of the European Society of Clinical Microbiology and Infectious Diseases (ESCMID). Determination of minimum inhibitory concentrations (MICs) of antibacterial agents by broth dilution. EUCAST discussion document E.dis. 5.1. Clin. Microbiol. Infec. 2003, 9, 1-7.

30. Cudic, M.; Condie, B.A; Weiner, D.J.; Lysenko, E.S.; Xiang, Z.Q.; Insug, O.; Bulet, P.; Otvos, L., Jr. Development of novel antibacterial peptides that kill resistant clinical isolates. Peptides 2002, 23, 2071-2083.

31. Devienne, K.F.; Raddi, M.S.G. Screening for antimicrobial activity of natural Products using a microplate photometer. Braz. J. Microbiol. 2002, 33, 166-168.

32. European Committee for Antimicrobial Susceptibility Testing (EUCAST) of the European Society of Clinical Microbiology and Infectious Diseases (ESCMID). Terminology relating to methods for the determination of susceptibility of bacteria to antimicrobial agents. EUCAST definitive document E. Def 1.2. Clin. Microbiol. Infec. 2000, 6, 503-508.

33. Fernandes, A., Jr.; Balestrin, E.C.; Betoni, J.E.C.; Orsi, R.O.; da Cunha, M.R.S.; Montelli, A.C. Propolis: Anti-Staphylococcus aureus activity and synergism with antimicrobial drugs. Memórias. Instituto. Oswaldo. Cruz 2005, 100, 563-566.

34. Mahon, C.R.; Manuselis, J.R.G. Textbook of Diagnostic Microbiology; W.B. Saunders: Philadelphia, PA, USA, 1995.

Sample Availability: Samples of the compounds and bacterial strains are available from the authors.

(C) 2014 by the authors; licensee MDPI, Basel, Switzerland. This article is an open access article distributed under the terms and conditions of the Creative Commons Attribution license (http://creativecommons.org/licenses/by/3.0/). 